\title{
Workshop: Impro Theatre
}

\author{
Dagmar Dörger and Martin Geisler
}

FH Erfurt, University of Applied Sciences, Altonaer Str. 25, 99085 Erfurt, Germany doerger@fh-erfurt.de, martin.geisler@fh-erfurt.de

\section{Workshop Abstract}

Interactive storytelling is also possible without a computer. Even a theatre play doesn't need to be based on a predefined text in order to be performed. A storyline in an improvisational play evolves dynamically from the input of the audience, from actions of the facilitator and from spontaneous ideas of the actors and actresses. The audience becomes an interactive element and - potentially - the actual author of the story. However, this doesn't mean that an Impro theatre play would not need a predefined concept. Also, the players and performers need at least basic training in the skills for impromptu acting. Even the development of a story that unfolds right in the moment of the performance needs basic assumptions. [1][2]

This workshop introduces basic rules, strategies and concepts that are useful for improvisers. The covered topics include

- rules and strategies of traditional Impro theatre, such as preparations, concepts of how to solve problems on stage, and consequences for modern interactive storytelling, as well as

- insights into the development of a storyline through a concrete Impro theatre play performed by the Erfurt group 'ImproVision'.

The workshop consists of the following four parts:

- Introduction: Background information on Impro theatre is provided in general, and particularly on the technique of an "Autorenspiel" (author play).

- Performance: During the performance of an "Autorenspiel", the audience becomes author of the play/story, and workshop participants experience how their ideas are transformed into this unique play.

- Basics and Techniques: Based on the outcome of the performance, the resulting story is analysed, in terms of its development and underlying structures, the techniques and possibilities of interaction, as well as limitations and problems on stage.

- Meta-Discussion: The overlapping aspects of digital and non-digital interactive storytelling are discussed.

\section{References}

1. Dörger, D., Nickel, H.-W.: Improvisationstheater - ein Überblick. Das Publikum als Auto. Schibri Verlag, Berlin (2008) (in German)

2. Johnstone, K.: Impro for Storytellers. Theatresports and the Art of Making Things Happen. Faber and Faber, London (1999) 